\title{
Blood pressure-lowering effect of Shinrin- yoku (Forest bathing): a systematic review and meta-analysis
}

\author{
Yuki Ideno ${ }^{1 *} \mathbb{D}$, Kunihiko Hayashi ${ }^{2}$, Yukina Abe ${ }^{3}$, Kayo Ueda ${ }^{4}$, Hiroyasu Iso ${ }^{5}$, Mitsuhiko Noda ${ }^{6}$, Jung-Su Lee ${ }^{7}$
} and Shosuke Suzuki ${ }^{8}$

\begin{abstract}
Background: Shinrin-yoku (experiencing the forest atmosphere or forest bathing) has received increasing attention from the perspective of preventive medicine in recent years. Some studies have reported that the forest environment decreases blood pressure. However, little is known about the possibility of anti-hypertensive applications of Shinrin-yoku. This study aimed to evaluate preventive or therapeutic effects of the forest environment on blood pressure.

Methods: We systematically reviewed the medical literature and performed a meta-analysis.Four electronic databases were systematically searched for the period before May 2016 with language restriction of English and Japanese. The review considered all published, randomized, controlled trials, cohort studies, and comparative studies that evaluated the effects of the forest environment on changes in systolic blood pressure. A subsequent meta-analysis was performed.
\end{abstract}

Results: Twenty trials involving 732 participants were reviewed. Systolic blood pressure of the forest environment was significantly lower than that of the non-forest environment. Additionally, diastolic blood pressure of the forest environment was significantly lower than that of the non-forest environment.

Conclusions: This systematic review shows a significant effect of Shinrin-yoku on reduction of blood pressure.

Keywords: Forest bathing, Blood pressure, Pulse rate, Systematic review, Meta-analysis

\section{Background}

Shinrin-yoku (experiencing the forest atmosphere or forest bathing) has received increasing attention from the perspective of preventive medicine in recent years [1-4]. Observational studies have suggested an association of exposure to nature and green vegetation with various health outcomes, including cardiovascular diseases [5]. Some experimental studies have reported the physiological effects of the forest environment (walking in, sitting in, and/or viewing the forest). They reported that the forest environment decreases levels of stress hormones [6-11], blood pressure [6, 12-14], and heart rate $(H R)[15,16]$, and induce relaxation effects. Changes in urinary adrenaline and noradrenaline

\footnotetext{
* Correspondence: y-ideno@gunma-u.ac.jp

${ }^{1}$ Gunma University Initiative for Advanced Research, 3-39-22 Showa-machi,

Maebashi City, Gunma 371-8511, Japan

Full list of author information is available at the end of the article
}

levels $[6,7,9,10,12]$ and HR reflect the autonomic nervous system. Additionally, the autonomic nervous system plays an important role in regulation of blood pressure. Taken together, these findings suggest that the forest environment causes a reduction in blood pressure or prevents hypertension. However, most previous studies did not have a sufficient sample size and their purpose was to examine the reduction of stress or induction of relaxation. Therefore, little is known regarding the possibility of anti-hypertensive applications of Shinrin-yoku.

This study aimed to evaluate preventive or therapeutic effects of the forest environment on blood pressure. We systematically reviewed the medical literature and performed a meta-analysis. Further, we examined if there were differences in effects according to the characteristics of participants, such as age, sex, and blood pressure, before intervention. 


\section{Methods}

\section{Selection criteria}

This review considered all published, randomized, controlled trials (RCTs), cohort studies, and comparative studies that evaluated the effects of the forest environment on changes in systolic blood pressure (SBP). Participants included adults.

\section{Outcome measures}

\section{Primary outcome}

The primary outcome was SBP. Provided there were sufficient included trials, sensitivity analyses were performed to explore the influence of the characteristics of participants, such as age, sex, and blood pressure, before intervention on effect size.

\section{Secondary outcomes}

The secondary outcomes included diastolic blood pressure (DBP) and $\mathrm{HR}$ or pulse rate (PR). In this review, we assumed that $\mathrm{HR}$ and $\mathrm{PR}$ were indices of autonomic nervous activity, and conducted the meta-analysis without distinguishing between them.

\section{Search strategy}

We searched electronic databases (PubMed, Cochrane library, CINAHL, and Japan Medical Abstracts Society Database) from their inception to May 2016 with language restriction of English and Japanese. We also searched the references of relevant studies. The search terms were as follows: (1) forest environment, OR forest area, OR shinrin, OR shinrin-yoku, OR shinrinyoku, OR forest walking, OR forest treatment, OR forest healing, OR forest remedy, OR forest therapy, OR forest basking, OR forest bathing, OR forest viewing, OR phytoncide; (2) blood pressure OR hypertension; (3) random, OR (single-blind method OR double-blind method), OR (single, OR double, OR treble, OR triple), OR (cohort, OR case-control, OR controlled study, OR control group, OR comparative study); and (4) 1, AND 2, AND 3.

\section{Data collection}

Three investigators (YA, YI, SS) extracted the literature, which were retrieved from the medical databases and manual searches. Two of three reviewers (YA, YI, KH) evaluated the full text of the extracted literature independently and discrepancies were resolved by discussion. We extracted

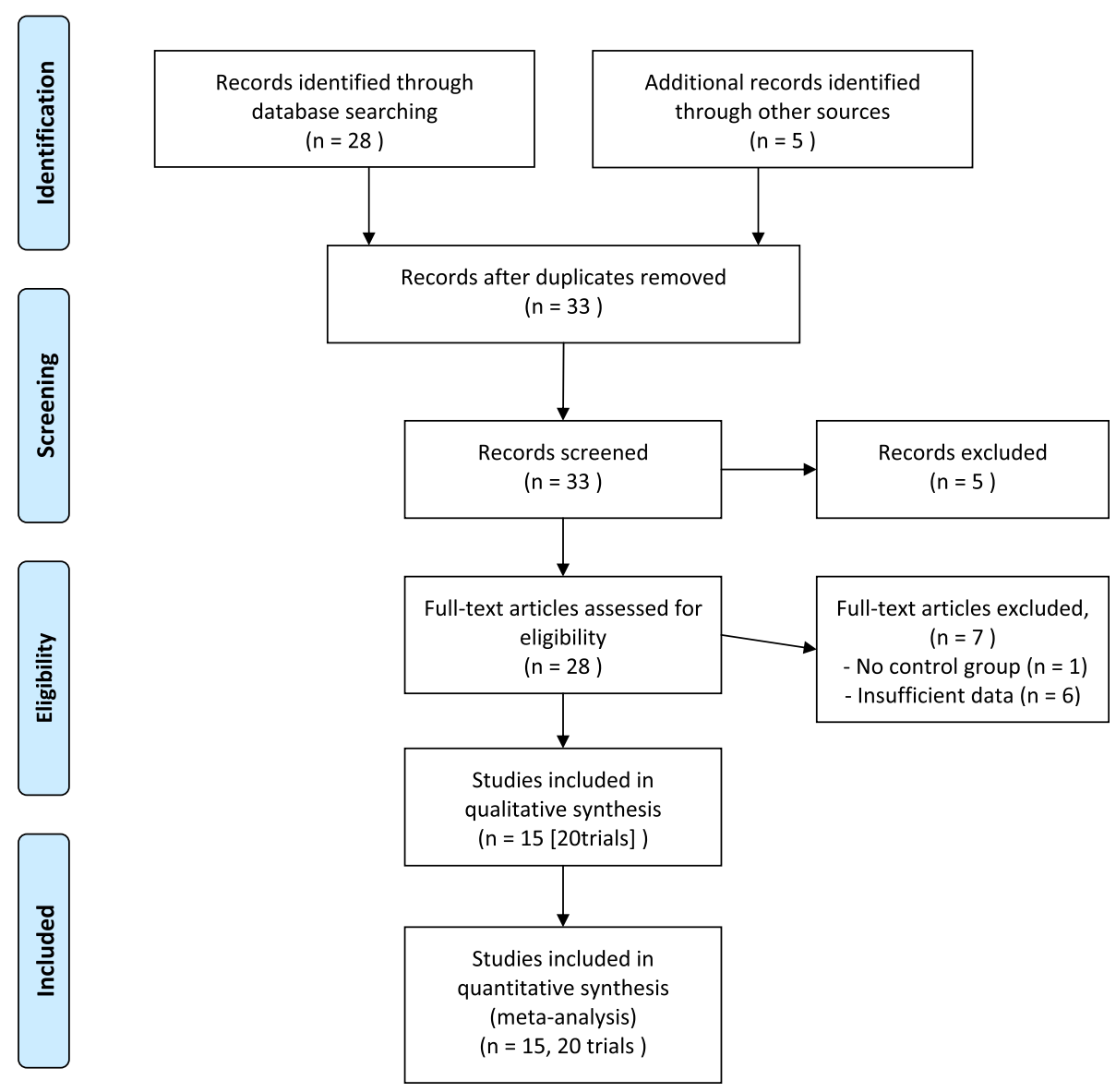

Fig. 1 Flow chart of the study selection process for the present study 
Table 1 Result of the meta-analysis comparing changes in SBP $(\mathrm{mmHg})$ between the forest environment and the non-forest environment based on 20 studies or subgroups

\begin{tabular}{|c|c|c|c|c|c|}
\hline Study or Subgroup & $\begin{array}{l}\text { Sinrin-yoku } \\
\text { Total }\end{array}$ & $\begin{array}{l}\text { Control } \\
\text { Total }\end{array}$ & Weight (\%) & $\begin{array}{l}\text { Mean Difference } \\
\text { IV, Fixed }\end{array}$ & $95 \% \mathrm{Cl}$ \\
\hline Ogushi et al., 2000 [18] & 37 & 20 & 1.0 & -5.00 & $-14.58-4.58$ \\
\hline Takayanagi \& Hagihara, 2005 [19] & 12 & 12 & 0.6 & -6.10 & $-19.02-6.82$ \\
\hline Tsunetsugu et al., 2007-2 [20] & 11 & * & 3.2 & -6.20 & $-11.65--0.75$ \\
\hline Tsunetsugu et al., 2007-1 [20, 40] & 9 & * & 3.3 & -2.50 & $-7.87-2.87$ \\
\hline Furuhashi et al., 2007 [22] & 12 & * & 7.8 & -3.90 & $-7.37--0.43$ \\
\hline Kozaki et al., 2007-1 [21] & 11 & * & 1.0 & -1.00 & $-10.62-8.62$ \\
\hline Kozaki et al., 2007-2 [21] & 11 & * & 1.2 & -1.30 & $-7.60-10.20$ \\
\hline Takeda et al., 2009-2 [30-35] & 8 & * & 1.3 & -10.00 & $-18.35--1.65$ \\
\hline Takeda et al., 2009-1 [30-35] & 11 & * & 0.5 & 1.10 & $-12.64-14.84$ \\
\hline Park et al., 2010-2 [23] & 75 & * & 20.9 & -2.16 & $-4.28--0.04$ \\
\hline Park et al., 2010-1 [23] & 268 & * & 35.4 & -2.16 & $-3.79--0.53$ \\
\hline Li et al., 2011 [10] & 16 & * & 0.9 & -3.00 & $-13.33-7.33$ \\
\hline Lee et al., 2011 [24] & 48 & * & 11.0 & -3.00 & $-5.92--0.08$ \\
\hline Kondo et al., 2011a [27, 29] & 8 & * & 2.9 & -4.00 & $-9.66-1.66$ \\
\hline Kondo et al., $2011 \mathrm{~b}[28,29]$ & 8 & * & 3.4 & -4.00 & $-9.23-1.23$ \\
\hline Sung et al., 2012 [25] & 28 & 28 & 1.5 & -8.70 & $-16.48--0.92$ \\
\hline Mao et al., 2012 [26] & 12 & 12 & 0.7 & -11.50 & $-22.87--0.13$ \\
\hline Kondo et al., 2014-1 [16] & 7 & * & 0.8 & -10.40 & $-21.43-0.63$ \\
\hline Kondo et al., 2014-2 [16] & 6 & * & 1.1 & -5.50 & $-14.73-3.73$ \\
\hline Lee \& Lee, 2014 [11] & 43 & 19 & 1.4 & -12.25 & $-20.36--4.14$ \\
\hline Total & 641 & $91^{* *}$ & 100.0 & -3.15 & $-4.12--2.18$ \\
\hline
\end{tabular}

$\mathrm{Cl}$, confidence interval; $\mathrm{df}$, degrees of freedom

${ }^{*}$ Cross-over design (same number as in Shinrin-yoku)

**Total number excluding the cross-over design

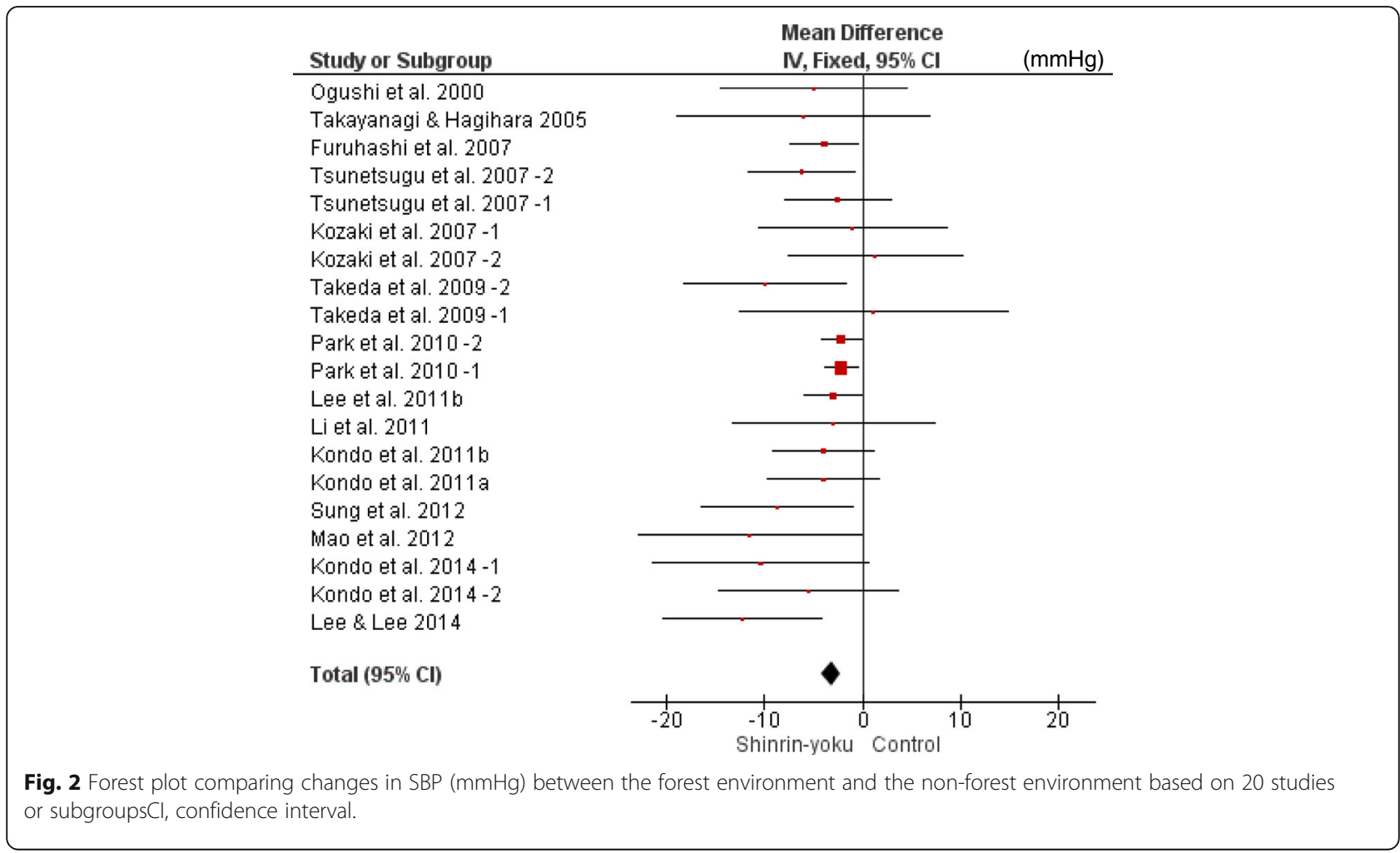


Table 2 Results of the meta-analysis of the change in SBP ( $\mathrm{mmHg})$ in the two subgroup analyses of SBP levels of 1$) \geq 130$ and 2) $<130 \mathrm{mmHg}$ before the intervention

\begin{tabular}{|c|c|c|c|c|c|}
\hline Study or Subgroup & $\begin{array}{l}\text { Sinrin-yoku } \\
\text { Total }\end{array}$ & $\begin{array}{l}\text { Control } \\
\text { Total }\end{array}$ & Weight (\%) & $\begin{array}{l}\text { Mean Difference } \\
\text { IV, Fixed }\end{array}$ & $95 \% \mathrm{Cl}$ \\
\hline \multicolumn{6}{|l|}{ 1) $\mathrm{SBP} \geq 130 \mathrm{mmHg}$} \\
\hline Tsunetsugu et al., 2007-2 [20] & 8 & * & 13.1 & -10.00 & $-18.35--1.65$ \\
\hline Tsunetsugu et al., 2007-1 [20, 40] & 11 & * & 4.8 & 1.10 & $-12.64-14.84$ \\
\hline Kondo et al., $2011 \mathrm{~b}[28,29]$ & 8 & * & 33.3 & -4.00 & $-9.23-1.23$ \\
\hline Li et al., 2011 [10] & 16 & * & 8.5 & -3.00 & $-13.33-7.33$ \\
\hline Sung et al., 2012 [25] & 28 & 28 & 15.1 & -8.70 & $-16.48--0.92$ \\
\hline Mao et al., 2012 [25] & 12 & 12 & 7.1 & -11.50 & $-22.87--0.13$ \\
\hline Kondo et al., 2014-1 [16] & 7 & * & 7.5 & -10.40 & $-21.43-0.63$ \\
\hline Kondo et al., 2014-2 [16] & 6 & * & 10.7 & -5.50 & $-14.73-3.73$ \\
\hline \multicolumn{6}{|l|}{ 2) $\mathrm{SBP}<130 \mathrm{mmHg}$} \\
\hline Ogushi et al., 2000 [18] & 37 & 20 & 3.1 & -5.00 & $-14.58-4.58$ \\
\hline Takayanagi \& Hagihara, 2005 [19] & 12 & 12 & 1.7 & -6.10 & $-19.02-6.82$ \\
\hline Furuhashi et al., 2007 [22] & 12 & * & 23.4 & -3.90 & $-7.37--0.43$ \\
\hline Tsunetsugu et al., 2007-1 [20, 40] & 9 & * & 9.8 & -2.50 & $-7.87-2.87$ \\
\hline Tsunetsugu et al., 2007-2 [20] & 11 & * & 9.5 & -6.20 & $-11.65--0.75$ \\
\hline Kozaki et al., 2007-1 [21] & 11 & * & 3.0 & -1.00 & $-10.62-8.62$ \\
\hline Kozaki et al., 2007-2 [21] & 11 & * & 3.6 & -1.30 & $-7.60-10.20$ \\
\hline Kondo et al., 2011a [27, 29] & 8 & * & 8.8 & -4.00 & $-9.66-1.66$ \\
\hline Lee et al., 2011 [24] & 48 & * & 33.0 & -3.00 & $-5.92--0.08$ \\
\hline Lee \& Lee, 2014 [11] & 43 & 19 & 4.3 & -12.25 & $-20.36--4.14$ \\
\hline Total & 202 & $51^{* *}$ & 100.0 & -3.85 & $-5.53--2.17$ \\
\hline
\end{tabular}

Heterogeneity: $\mathrm{Chi}^{2}=4.73, \mathrm{df}=7(P=0.69) ; \mathrm{I}^{2}=0 \%$

Test for overall effect: $Z=4.11(P<0.0001)$

Heterogeneity: $\mathrm{Chi}^{2}=7.20, \mathrm{df}=9(P=0.62) ;\left.\right|^{2}=0 \%$

Test for overall effect: $Z=4.50(P<0.00001)$

$\mathrm{Cl}$, confidence interval; $\mathrm{df}$, degrees of freedom

*Cross-over design (same number as in Shinrin-yoku)

**Total number excluding the cross-over design

information on the following: study characteristics (authors, country, design, year of publication, sample size, duration of intervention, and follow-up); participants' characteristics (age, sex); intervention (forest exposure and comparators); and outcomes (blood pressure and HR or PR). We extracted the mean change from baseline and standard deviation (SD) and/or before and after mean scores and corresponding SDs.

\section{Risk of bias}

Risk of bias was assessed using Cochrane's risk of bias tool (random sequence generation, allocation concealment, blinding of participants and personnel, blinding of outcome assessor, incomplete outcome data, selective reporting, other bias).

\section{Data analysis}

Treatment effect size was standardized by mean differences (MDs) that were obtained by dividing changes from baseline (or the difference between before and after treatment) by the pooled SD. Results for the comparative effect are shown by the mean difference estimates and 95\% confidence intervals (CIs). We used a standard inverse variance random effects model for meta-analyses. Heterogeneity was assessed by $\mathrm{I}^{2}$ statistics. Publication bias or small study effects were checked by the conventional funnel plot. Statistical analyses were performed by Cochrane Review Manager software (RevMan) ver5.1 (The Nordic Cochrane Center, The Cochrane Collaboration). When we used the generic inverse variance method to incorporate cross-over studies into the meta-analysis, we used the formula listed in the Cochrane Handbook for Systematic Reviews of Interventions, section 16.4.6.1 [17], to calculate the SD of the difference between treatment and control. This study was registered as PROSPERO CRD42016038286.

\section{Results}

\section{Results of the search}

The initial search identified 33 records, of which 28 full papers were identified for further examination. We excluded five papers on the basis of their abstracts because they did not meet the selection criteria of the study design. After screening the full text of the 28 selected papers, 21 met the inclusion criteria; seven were excluded because of no control 


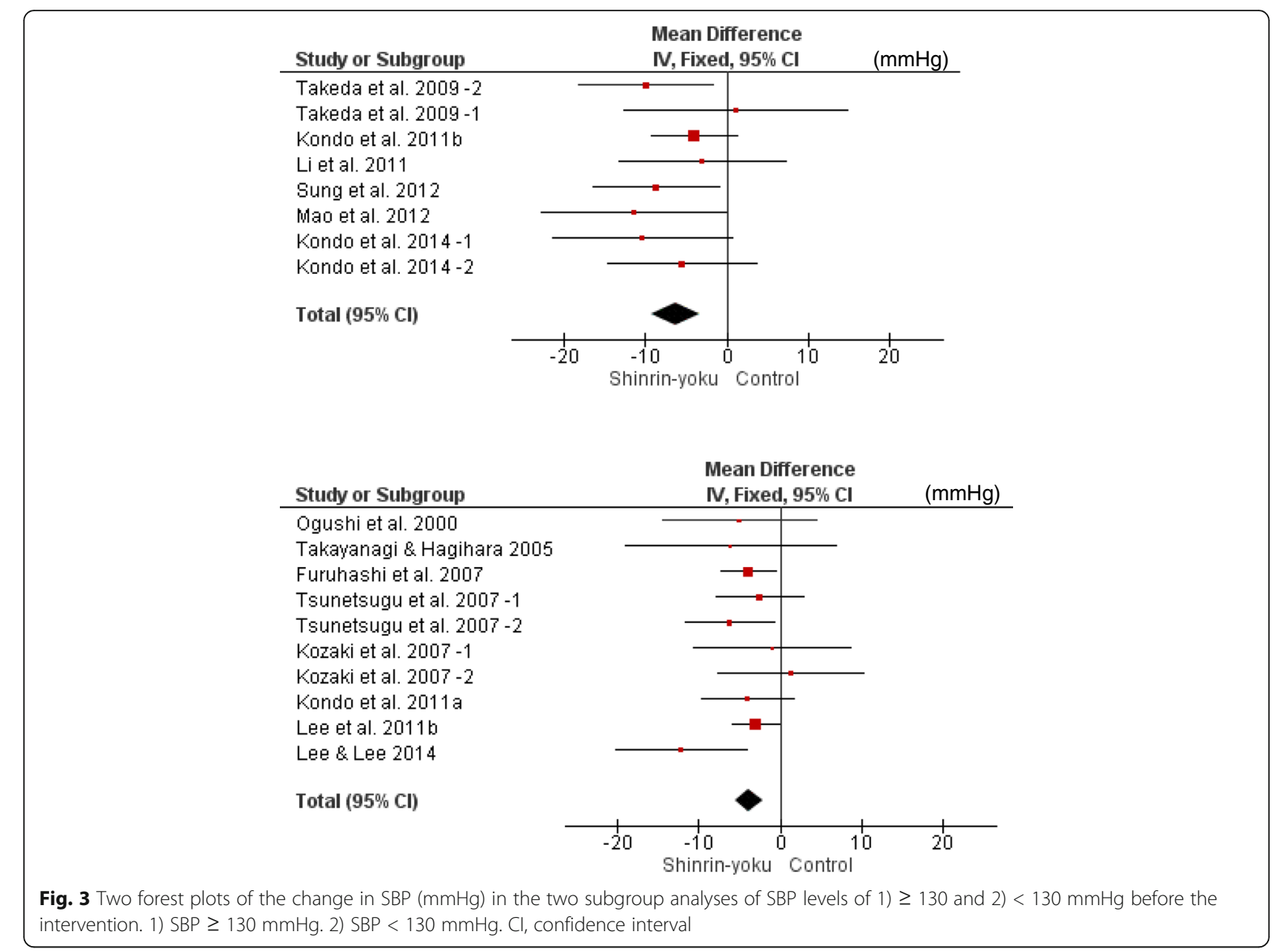

group $(n=1)$ or insufficient data $(n=6)$. Figure 1 shows the details of the study selection process. Because these 21 papers included duplicated papers of identical studies, we identified 15 studies, including 12 studies from 12 papers [10, 11, 16, 18-26], two studies from three papers [27-29], and one study from six papers [30-35]. Additionally, two papers reported outcomes according to sex $[16,30]$, and three papers reported outcomes separately according to two intervention methods [20, 21, 23]. Therefore, we considered them as separate trials, and finally included 20 trials in analyses. To distinguish these separate trials, we added the numbers "-1" and "-2" to the dates of the trials (Additional file 1).

\section{Study design}

A detailed description of the characteristics of included trials is shown in Additional file 1. Of these 20 trials, five were parallel-group comparison studies and 15 were cross-over studies.

\section{Participants}

In total, 732 participants were included in the 20 trials. Sample sizes ranged from 6 to 268, and the median size was 12 participants. The mean age of participants in included trials ranged from 18 to 80 years. Participants of 12 trials were only males, four trials included only females, and four trials did not distinguish sex.

\section{Interventions}

All trials used the forest environment. The main intervention methods were walking in forest areas (11 trials), and sitting and viewing forest landscapes (7 trials). These intervention methods were compared with the same activities in non-forest environment-like city areas (13 trials), with sitting in a room (4 trials), or with only measuring blood pressure in daily life ( 2 trials). The duration of interventions in most trials was within $2 \mathrm{~h}$ (16 trials), but the duration of two trials was longer than 1 day.

\section{Outcomes}

Of the 20 trials that reported values of SBP, 17 reported values of DBP, five reported values of HR, and eight reported values of PR. 
Table 3 Results of the meta-analysis of the change in SBP $(\mathrm{mmHg})$ in the two subgroup analyses of differences in intervention methods (walking and non-walking)

\begin{tabular}{|c|c|c|c|c|c|}
\hline Study or Subgroup & $\begin{array}{l}\text { Sinrin-yoku } \\
\text { Total }\end{array}$ & $\begin{array}{l}\text { Control } \\
\text { Total }\end{array}$ & Weight (\%) & $\begin{array}{l}\text { Mean Difference } \\
\text { IV, Fixed }\end{array}$ & $95 \% \mathrm{Cl}$ \\
\hline \multicolumn{6}{|l|}{ 1) Walking group } \\
\hline Ogushi et al., 2000 [18] & 37 & 20 & 3.1 & -5.00 & $-14.58-4.58$ \\
\hline Kozaki et al., 2007-1 [21] & 11 & * & 3.1 & -1.00 & $-10.62-8.62$ \\
\hline Tsunetsugu et al., 2007-1 [20,40] & 9 & * & 9.9 & -2.50 & $-7.87-2.87$ \\
\hline Takeda et al., 2009-1 [30-35] & 11 & * & 1.5 & 1.10 & $-12.64-14.84$ \\
\hline Takeda et al., 2009-2 [30-35] & 8 & * & 4.1 & -10.00 & $-18.35--1.65$ \\
\hline Park et al., 2010-2 [23] & 75 & * & 63.5 & -2.16 & $-4.28--0.04$ \\
\hline Li et al., 2011 [10] & 16 & * & 2.7 & -3.00 & $-13.33-7.33$ \\
\hline Mao et al., 2012 [26] & 12 & 12 & 2.2 & -11.50 & $-22.87--0.13$ \\
\hline Kondo et al., 2014-1 [16] & 7 & * & 2.3 & -10.40 & $-21.43-0.63$ \\
\hline Lee \& Lee, 2014 [11] & 43 & 19 & 4.3 & -12.25 & $-20.36--4.14$ \\
\hline Kondo et al., 2014-2 [16] & 6 & * & 3.3 & -5.50 & $-14.73-3.73$ \\
\hline Total & 235 & $51^{* *}$ & 100.0 & -3.48 & $-5.17--1.80$ \\
\hline \multicolumn{6}{|l|}{ 2) Non-walking group } \\
\hline Takayanagi \& Hagihara, 2005 [19] & 12 & 12 & 0.8 & -6.10 & $-19.02-6.82$ \\
\hline Kozaki et al., 2007-2 [21] & 11 & * & 1.8 & -1.30 & $-7.60-10.20$ \\
\hline Tsunetsugu et al., 2007-2 [20] & 11 & * & 4.7 & -6.20 & $-11.65--0.75$ \\
\hline Furuhashi et al., 2007 [22] & 12 & * & 11.6 & -3.90 & $-7.37--0.43$ \\
\hline Park et al., 2010-1 [23] & 268 & * & 52.9 & -2.16 & $-3.79--0.53$ \\
\hline Kondo et al., 2011b [27-29] & 8 & * & 5.1 & -4.00 & $-9.23-1.23$ \\
\hline Lee et al., 2011 [24] & 48 & * & 16.4 & -3.00 & $-5.92--0.08$ \\
\hline Kondo et al., 2011a [27, 29] & 8 & * & 4.4 & -4.00 & $-9.66-1.66$ \\
\hline Sung et al., 2012 [25] & 28 & 28 & 2.3 & -8.70 & $-16.48--0.92$ \\
\hline Total & 406 & $40^{* *}$ & 100.0 & -2.99 & $-4.17--1.80$ \\
\hline
\end{tabular}

Heterogeneity: $\mathrm{Chi}^{2}=12.85, \mathrm{df}=10(P=0.23) ; \mathrm{I}^{2}=22 \%$

Test for overall effect: $Z=4.05(P<0.0001)$

Heterogeneity: $\mathrm{Chi}^{2}=6.05, \mathrm{df}=8(P=0.64) ; \mathrm{I}^{2}=0 \%$

Test for overall effect: $Z=4.95(P<0.00001)$

$\mathrm{Cl}$, confidence interval; $\mathrm{df}$, degrees of freedom

${ }^{*}$ Cross-over design (same number as in Shinrin-yoku)

**Total number excluding the cross-over design

\section{Countries}

Trials were conducted in three countries, with 17 trials conducted in Japan, two in Korea, and one in China.

\section{Systolic blood pressure}

The meta-analysis was conducted using all 20 trials. SBP of the forest environment was significantly lower than that of the non-forest environment (MD $-3.15 \mathrm{mmHg} ; 95 \% \mathrm{CI}$ -4.12 to $-2.18 ; P<0.001 ; \mathrm{I}^{2}=1 \% ; 732$ participants; 20 trials) (Table 1, Fig. 2). They were divided into the SBP $\geq 130 \mathrm{mmHg}$ group and the SBP $<130 \mathrm{mmHg}$ group to investigate heterogeneous effects in hypertensive and normotensive subjects, and meta-analyses were conducted. In both groups, SBP of the forest environment was significantly lower than that in the non-forest environment (SBP $\geq 130 \mathrm{mmHg}$ : MD $-6.33 \mathrm{mmHg}$; 95\% CI -9.35 to $-3.31 ; P<0.001 ; \mathrm{I}^{2}=0 \%$;
136 participants; 8 trials, SBP < 130 mmHg: MD $-3.85 \mathrm{mmHg}$; $95 \% \mathrm{CI}-5.53$ to $-2.17 ; P<0.001 ; \mathrm{I}^{2}=0 \%$; 253 participants; 10 trials) (Table 2, Fig. 3 ).

We then divided these trials into the walking group and the non-walking group to examine the difference in intervention methods, and conducted meta-analyses. In both groups, SBP of the forest environment was lower than that of the non-forest environment (walking: $\mathrm{MD}$ $-3.48 \mathrm{mmHg} ; 95 \% \mathrm{CI}-5.17$ to $-1.80 ; \quad P<0.001$; $\mathrm{I}^{2}=22 \%$; 286 participants; 11 trials, non-walking: MD $-2.99 \mathrm{mmHg}$; $95 \% \mathrm{CI}-4.17$ to $-1.80 ; P<0.001 ; \mathrm{I}^{2}=0 \%$; 446 participants; 9 trials) (Table 3, Fig. 4). Additionally, the trials were divided into the young male group, the middle-aged or older male group, and the middle-aged or older female group to examine differences in age and sex. Meta-analyses were then conducted. In all of the 


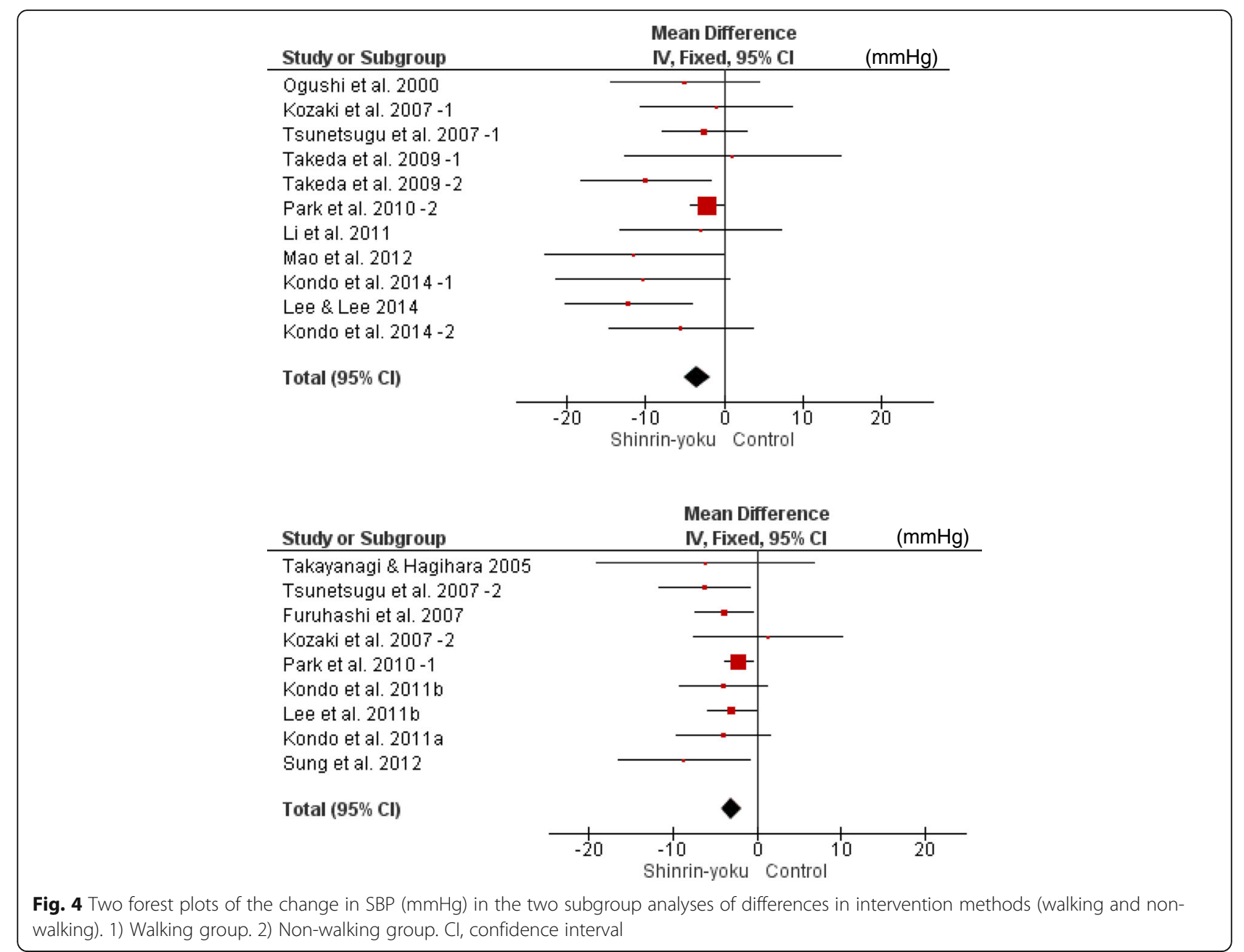

groups, SBP of the forest environment was lower than that of the non-forest environment (young males: MD $-2.53 \mathrm{mmHg} ; 95 \% \mathrm{CI}-3.59$ to $-1.48 ; P<0.001$; $\mathrm{I}^{2}=0 \% ; 445$ participants; 8 trials, middle-aged or older males: $\mathrm{MD}-4.27 \mathrm{mmHg} ; 95 \%$ CI -8.38 to $-0.17 ; P=0.04 ; \mathrm{I}^{2}=0 \% ; 42$ participants; 4 trials, middle-aged or older females: MD $-7.16 \mathrm{mmHg}$; $95 \%$ CI -10.88 to $-3.45 ; P<0.001 ; \mathrm{I}^{2}=8 \% ; 84$ participants; 4 trials) (Table 4, Fig. 5).

\section{Diastolic blood pressure}

Seventeen trials were suitable for meta-analysis. DBP of the forest environment was significantly lower than that of the non-forest environment (MD $-1.75 \mathrm{mmHg}$; 95\% CI -2.38 to $-1.13 ; P<0.001 ; \mathrm{I}^{2}=24 \% ; 705$ participants; 17 trials).

\section{Heart rate and pulse rate}

Five trials reported values of HR and eight trials reported values of PR. We conducted meta-analysis using these 13 trials. HR and PR of the forest environment were significantly lower than those of the non-forest environment (MD $-3.84 \mathrm{bpm}$; 95\% CI -5.27 to -2.40 ; $P<0.001 ; \mathrm{I}^{2}=39 \% ; 563$ participants; 13 trials).

\section{Publication bias}

The funnel plot demonstrated that toward the bottom of the graph most studies appear toward the left (indicating more risk), which is consistent with the possibility that some studies are missing from the right (Fig. 6). But, this plot showed an almost symmetrical shape. It suggested weak evidence of publication bias.

\section{Discussion}

This systematic review examined the evidence for effects of the forest environment on blood pressure. The review identified 20 trials (15 studies), involving 732 participants. The majority of trials were cross-over studies (15 trials), and only five trials were parallel-group comparison studies, which had a separate control group from the experimental group. The results of meta-analysis showed that SBP and DBP of the forest environment were significantly lower than those of the non-forest environment. Taken 
Table 4 Results of the meta-analysis of the change in SBP $(\mathrm{mmHg})$ in the two subgroup analyses of the three groups of sex and age differences

\begin{tabular}{|c|c|c|c|c|c|}
\hline Study or Subgroup & $\begin{array}{l}\text { Sinrin-yoku } \\
\text { Total }\end{array}$ & $\begin{array}{l}\text { Control } \\
\text { Total }\end{array}$ & Weight (\%) & $\begin{array}{l}\text { Mean Difference } \\
\text { IV, Fixed }\end{array}$ & $95 \% \mathrm{Cl}$ \\
\hline \multicolumn{6}{|c|}{ 1) Young male (university student) group } \\
\hline Kozaki et al., 2007-2 [21] & 11 & * & 1.4 & -1.30 & $-7.60-10.20$ \\
\hline Kozaki et al., 2007-1 [21] & 11 & * & 1.2 & -1.00 & $-10.62-8.62$ \\
\hline Tsunetsugu et al., 2007-1 [20, 40] & 9 & * & 3.9 & -2.50 & $-7.87-2.87$ \\
\hline Furuhashi et al., 2007 [22] & 12 & * & 9.3 & -3.90 & $-7.37--0.43$ \\
\hline Tsunetsugu et al., 2007-2 [20] & 11 & * & 3.8 & -6.20 & $-11.65--0.75$ \\
\hline Park et al., 2010-2 [23] & 75 & * & 25.0 & -2.16 & $-4.28--0.04$ \\
\hline Park et al., 2010-1 [23] & 268 & * & 42.3 & -2.16 & $-3.79--0.53$ \\
\hline Lee et al., 2011 [24] & 48 & * & 13.1 & -3.00 & $-5.92--0.08$ \\
\hline Total & 445 & $0^{* *}$ & 100.0 & -2.53 & $-3.59--1.48$ \\
\hline \multicolumn{6}{|l|}{ 2) Middle-aged or older male group } \\
\hline Takeda et al., 2009-1 [30-35] & 11 & * & 8.9 & 1.10 & $-12.64-14.84$ \\
\hline Li et al., 2011 [10] & 16 & * & 15.8 & -3.00 & $-13.33-7.33$ \\
\hline Kondo et al., $2011 \mathrm{~b}[28,29]$ & 8 & * & 61.5 & -4.00 & $-9.23-1.23$ \\
\hline Kondo et al., 2014-1 [16] & 7 & * & 13.8 & -10.40 & $-21.43-0.63$ \\
\hline Total & 42 & $0^{* *}$ & 100.0 & -4.27 & $-8.38--0.17$ \\
\hline \multicolumn{6}{|c|}{ 3) Middle-aged or older female group } \\
\hline Takeda et al., 2009-2 [30-35] & 8 & * & 19.8 & -10.00 & $-18.35--1.65$ \\
\hline Kondo et al., 2011a [27, 29] & 8 & * & 43.0 & -4.00 & $-9.66-1.66$ \\
\hline Kondo et al., 2014-2 [16] & 6 & * & 16.2 & -5.50 & $-14.73-3.73$ \\
\hline Lee \& Lee, 2014 [11] & 43 & 19 & 21.0 & -12.25 & $-20.36--4.14$ \\
\hline Total & 65 & $19^{* *}$ & 100.0 & -7.16 & $-10.88--3.45$ \\
\hline
\end{tabular}

Heterogeneity: $\mathrm{Chi}^{2}=3.57, \mathrm{df}=7(P=0.83) ; \mathrm{I}^{2}=0 \%$

Test for overall effect: $Z=4.70(P<0.00001)$

Heterogeneity: $\mathrm{Chi}^{2}=3.28, \mathrm{df}=3(P=0.35) ; \mathrm{I}^{2}=8 \%$

Test for overall effect: $Z=3.78(P<0.0002)$

$\mathrm{Cl}$, confidence interval; $\mathrm{df}$, degrees of freedom

${ }^{*}$ Cross-over design (same number as in Shinrin-yoku)

**Total number excluding the cross-over design

together, these findings suggest that the forest environment may have anti-hypertensive effects.

For analysis according to participants' characteristics, we conducted sub-group analyses considering SBP levels before intervention and age. The trials were divided into the high SBP group ( $\geq 130 \mathrm{mmHg}$ ) and the low SBP group (< $130 \mathrm{mmHg}$ ) according to the value of SBP before intervention. Meta-analysis showed that SBP of the forest environment was significantly lower than that of the non-forest environment. When we compared the MD of both groups, the MD in the high SBP group was lower than that in the low SBP group. This finding suggests that the forest environment may have a larger effect on lowering SBP in hypertensive people than in normotensive people.

We then divided subjects into the young male group, the middle-aged or older male group, and the middleaged or older female group. Although all of the groups showed that SBP of the forest environment was lower than that of the non-forest environment, the MD of the older groups was lower than that of the younger group. This finding suggests that the forest environment has a larger effect on lowering SBP in older people than in younger people. However, all trials for male university students comprised the low SBP group and blood pressure rises with age. Therefore, rather than being affected by age, the forest environment might have a larger effect on lowering SBP in people with higher blood pressure than in those with lower blood pressure.

An observational study showed a positive association of exposure to the forest environment with reduced blood pressure in children [36]. However, the mechanism of how the forest environment reduces blood pressure is unclear. The present systematic review showed that $H R$ and PR, which were evaluated as indices of autonomic nervous activity, were significantly decreased after the interventions. This finding indicates that the forest environment reduces sympathetic nerve activity and increases parasympathetic nerve activity. Additionally, some studies have reported that the forest environment significantly reduces urinary adrenaline and noradrenaline levels $[6,7,9,10,12]$. Adrenaline and noradrenaline levels are indices of autonomic nervous activity, and their reduction suggests that sympathetic 


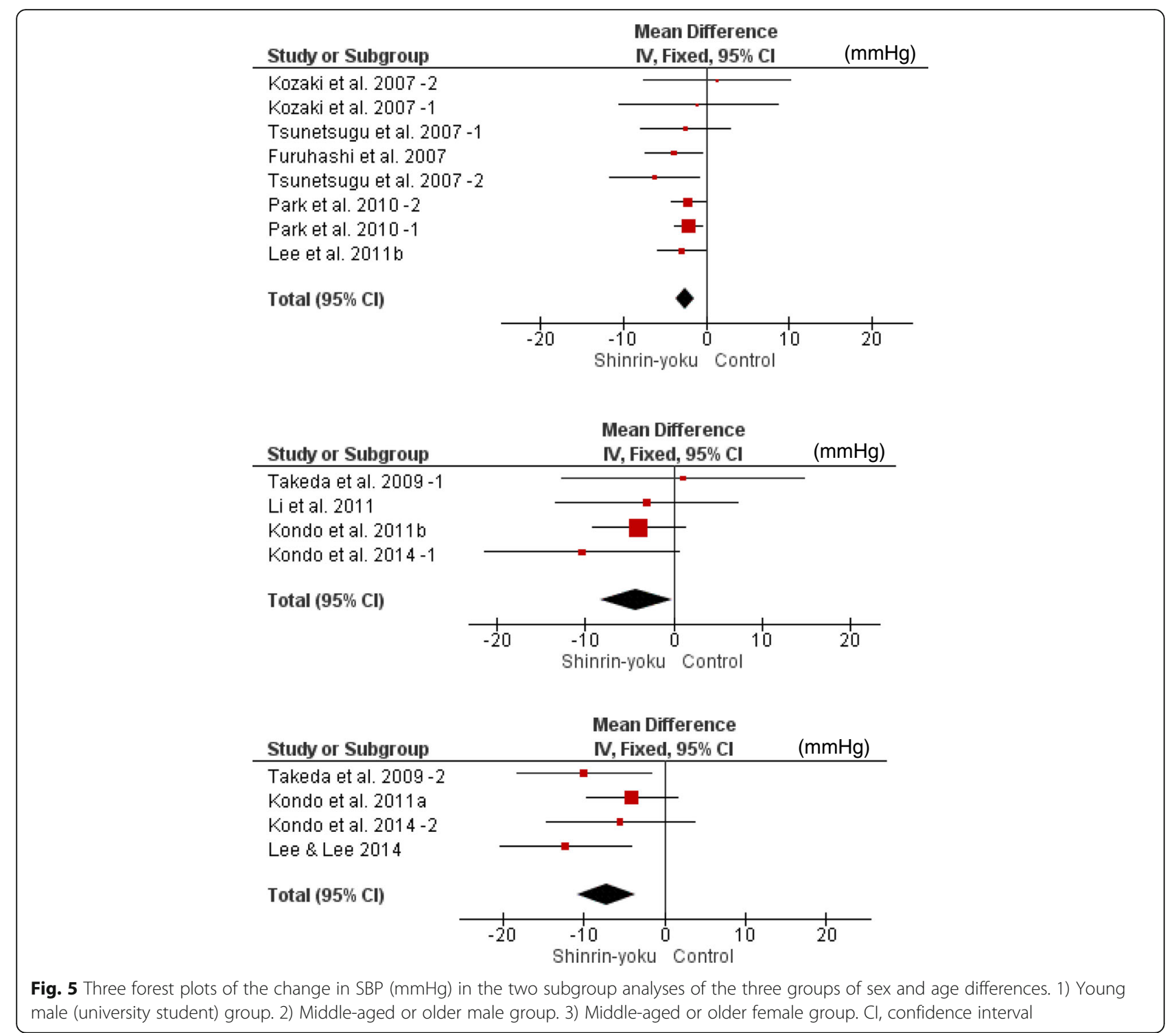

nerve activity is reduced. This review suggests that the autonomic nervous system plays an important role in the regulation of blood pressure.

We also divided the trials into the walking group and the non-walking group to examine differences in intervention methods, and conducted sub-group meta-analyses. In both groups, SBP of the forest environment was significantly lower than that in the non-forest environment. There was not a large difference in the MD between these groups. This finding suggests that the effect of the forest environment on blood pressure is not due to physical activity. Some studies have shown that phytoncides (wood essential oil) may have a beneficial effect on blood pressure [10, 37]. Further study is necessary because some factors in the forest environment reduce blood pressure.

This study has several limitations. First, because most trials investigated only immediate effects of the forest environment, we could not evaluate long-term effects. There were only two trials in which the intervention or observation period was longer than 1 day $[25,26]$, of which Sung et al. [25] used 3 days and Mao et al. [26] used 7 days. Both trials showed that SBP of the forest environment was significantly lower than that of the non-forest environment. However, Sung et al. [25] also reported that $\mathrm{SBP}$ at 8 weeks after a 3-day forest therapy program was not significantly different between the forest therapy group and the control group. These findings suggest that repeated exposure to the forest environment may be needed to obtain long-term benefits. Second, we could not characterize individual differences in responses. Although there are individual differences in effects of natural environments, research methods have not been clearly established. Song et al. [38] described that individual differences in responses to forest environments can be 


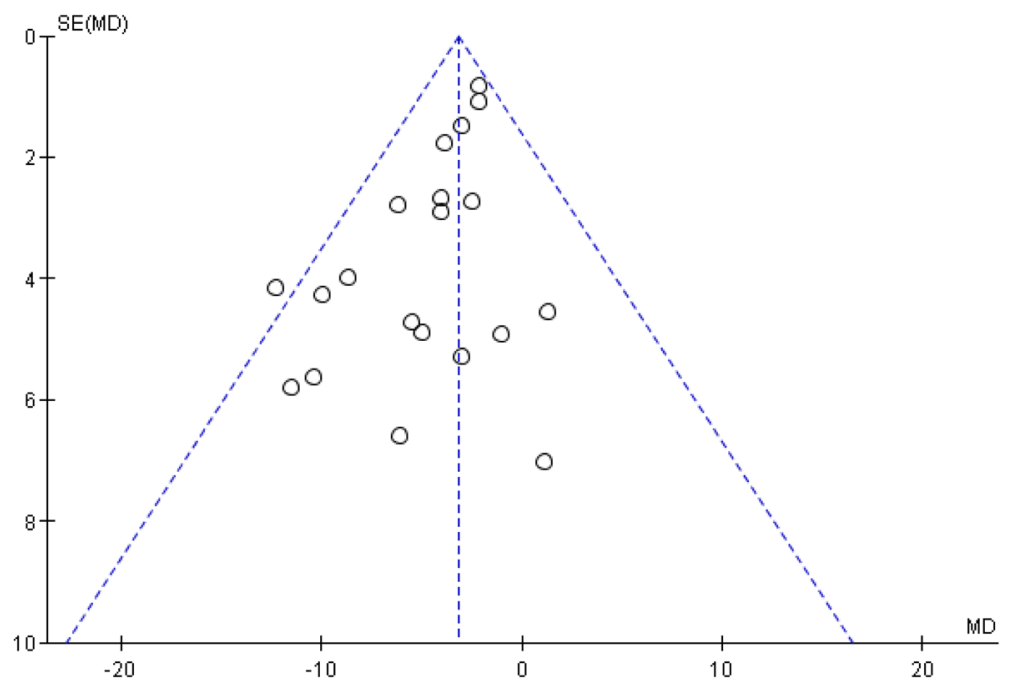

Fig. 6 Funnel plot, using data from 20 trials of therapeutic effects of the forest environment on systolic blood pressure. SE, standard error; MD, mean difference

explained by type A and Type B behavior patterns. Additionally, Wilder formulated the "law of initial value", which states that "the higher this 'initial level', the smaller is the response to function-raising, the greater is the response to function-depressing agents" [39]. Some studies have reported a significant negative correlation between baseline and the amount of change in the forest environment, such as salivary cortisol concentrations [40] and blood pressure [41]. However, because 15 of 20 trials that were included in this review were cross-over studies, considering individual differences is not so important. Third, we did not consider antihypertensive medication in this review. Further study taking this medication into account is required.

The second term of the National Health Promotion Movement in the twenty-first century (Health Japan 21 [the second term]) estimates that lowering average systolic blood pressure by $4 \mathrm{mmHg}$ will lead to a reduction in mortality rate of cerebrovascular disease (males, $8.9 \%$; females, 5.8 ) and in mortality rate of ischemic heart disease (males, 5.4\%; females, 7.2), among 40- to 89-year-old people whose prevalence of high blood pressure is high [42, 43]. Our study showed that the forest environment reduced SBP by $6.33 \mathrm{mmHg}$ in the high SBP group, by $4.27 \mathrm{mmHg}$ in the middle-aged or older male group, and by $7.16 \mathrm{mmHg}$ in the middle-aged and older female group. Therefore, we believe that the forest environment can have antihypertensive effects and contribute to health promotion for middle-aged or older people.

\section{Conclusions}

This systematic review shows significant effects of the forest environments on a reduction in blood pressure. In particular, the forest environment has a larger effect on lowering SBP in people with high blood pressure and in middle-aged or older people compared with the nonforest environment.

\section{Additional file}

Additional file 1: Characteristics of included studies. (XLSX $16 \mathrm{~kb}$ )

\section{Acknowledgements}

We thank Tomomi Ushiki for valuable advice on searching articles as a librarian.

\section{Funding}

This work was supported by a Health Labour Sciences Research Grant (Comprehensive Research on Life-Style Related Diseases including Cardiovascular Diseases and Diabetes Mellitus, H25-ippan-029) from the Ministry of Health, Labour and Welfare in Japan.

\section{Availability of data and materials}

Because we used only published articles, anyone can access them. Besides, everyone can check this study protocol which was registered as PROSPERO CRD42016038286.

\section{Authors' contributions}

$\mathrm{KH}$ contributed to the conception and design of the work. $\mathrm{KU}, \mathrm{HI}, \mathrm{MN}$, and JSL contributed to the conception. YI, KH, YA, and SS contributed to the acquisition, analysis, and interpretation of data for the work. YI and YA drafted the manuscript. $\mathrm{KH}, \mathrm{KU}, \mathrm{HI}, \mathrm{MN}$, JSL, and SS critically revised the manuscript for important intellectual content. All gave final approval and agree to be accountable for all aspects of work ensuring integrity and accuracy.

Ethics approval and consent to participate

Not applicable.

Consent for publication

Not applicable.

Competing interests

The authors declare that they have no competing interests. 


\section{Publisher's Note}

Springer Nature remains neutral with regard to jurisdictional claims in published maps and institutional affiliations.

\begin{abstract}
Author details
'Gunma University Initiative for Advanced Research, 3-39-22 Showa-machi, Maebashi City, Gunma 371-8511, Japan. ${ }^{2}$ Graduate School of Health Science, Gunma University, 3-39-22 Showa-machi, Maebashi City, Gunma 371-8511, Japan. ${ }^{3}$ Tochigi Prefectural Western District Health and Welfare Services Center, 1664-1 Imamiya-cho, Kanuma City, Tochigi 322-0068, Japan. ${ }^{4}$ Department of Environmental Engineering, Kyoto University Graduate School of Engineering, Yoshida Honmachi, Sakyo-ku, Kyoto 606-8501, Japan. ${ }^{5}$ Public Health, Department of Social and Medicine, Graduate School of Medicine, Osaka University, 1-1 Yamadaoka, Suita, Osaka 565-0871, Japan. ${ }^{6}$ Department of Endocrinology and Diabetes, Saitama Medical University, 38 Morohongo, Moroyama-cho, Iruma-gun, Saitama 350-0495, Japan. ${ }^{7}$ School of Public Health, Graduate School of Medicine, The University of Tokyo, 7-3-1 Hongo, Bunkyo-ku, Tokyo 113-8654, Japan. ${ }^{8}$ Professor Emeritus, Gunma University and NPO International Eco-Health Research Group, 3-39-22 Showa-machi, Maebashi City, Gunma 371-8511, Japan.
\end{abstract}

\section{Received: 9 December 2016 Accepted: 7 August 2017} Published online: 16 August 2017

\section{References}

1. Tsunetsugu Y, Park BJ, Miyazaki Y. Trend in research related to "Shinrin-yoku" (taking in the forest atmosphere or forest bathing) in Japan. Environ Health Prev Med. 2010;15:27-37.

2. Lee J, Park BJ, Tsunetsugu Y, Ohira T, Kagawa T, Miyazaki Y. Effect of forest bathing on physiological and psychological responses in young Japanese male subjects. Public Health. 2011;125:93-100.

3. Li Q, Kawada T. Possibility of clinical applications of forest medicine. Nihon Eiseigaku Zasshi (Jpn J Hyg). 2014;69:117-21. (in Japanese)

4. Miyazaki $Y$, Ikei $H$, Song C. Forest medicine research in Japan. Nihon Eiseigaku Zasshi (Jpn J Hyg). 2014;69:122-35. (in Japanese)

5. James P, Banay RF, Hart JE, Laden F. A review of the health benefits of greenness. Curr Epidemiol Rep. 2015:2:131-42.

6. Li Q, Morimoto K, Kobayashi M, Inagaki H, Katsumata M, Hirata Y, Hirata K, Suzuki H, Li YJ, Wakayama Y, Kawada T, Park BJ, Ohira T, Matsui N, Kagawa T, Miyazaki $Y$, Krensky AM. Visiting a forest, but not a city, increases human natural killer activity and expression of anti-cancer proteins. Int J Immunopathol Pharmacol. 2008;21:117-27.

7. Li Q, Morimoto K, Kobayashi M, Inagaki H, Katsumata M, Hirata Y, Hirata K, Shimizu T, Li YJ, Wakayama Y, Kawada T, Ohira T, Takayama N, Kagawa T, Miyazaki Y. A forest bathing trip increases human natural killer activity and expression of anti-cancer proteins in female subjects. J Biol Regul Homeost Agents. 2008;22:45-55.

8. Park BJ, Tsunetsugu Y, Ishii H, Furuhashi S, Hirano H, Kagawa T, Miyazaki Y. Physiological effects of Shinrin-yoku (taking in the atmosphere of the forest) in a mixed forest in Sinano town, Japan. Scand J For Res. 2008;23:278-83.

9. Li Q, Kobayashi M, Inagaki H, Hirata Y, Li YJ, Hirata K, Shimizu T, Suzuki H, Katsumata M, Wakayama Y, Kawada T, Ohira T, Matsui N, Kagawa T. A day trip to a forest park increases human natural killer activity and the expression of anticancer proteins in male subjects. J Biol Regul Homeost Agents. 2010;24:157-65.

10. Li Q, Otsuka T, Kobayashi M, Wakayama Y, Inagaki H, Katsumata M, Hirata Y, Li YJ, Hirata K, Shimizu T, Suzuki H, Kawada T, Kagawa T. Acute effects of walking in forest environments on cardiovascular and metabolic parameters. Eur J Appl Physiol. 2011;111:2845-53.

11. Lee JY, Lee DC. Cardiac and pulmonary benefits of forest walking versus city walking in elderly women: a randomised, controlled, open-label trial. Eur J Integr Med. 2014;6:5-11.

12. Ochiai H, Ikei H, Song C, Kobayashi M, Takamatsu A, Miura T, Kagawa T, Li Q, Kumeda S, Imai M, Miyazaki Y. Physiological and psychological effects of forest therapy on middle-aged males with high-normal blood pressure. Int J Environ Res Public Health. 2015;12:2532-42.

13. Lee J, Park BJ, Tsunetsugu Y, Kagawa T, Miyazaki Y. Restoractive effects of viewing real forest landscapes, based on a comparison with urban landscapes. Scand J For Res. 2009:24:227-34

14. Park BJ, Tsunetsugu Y, Kasetani T, Morikawa T, Kagawa T, Miyazaki Y Physiological effects of forest recreation in a young conifer forest in Hinokage town, Japan. Silva Fennica. 2009;43:291-301.
15. Matsuba N, Lee J, Park BJ, Lee M, Song C, Miyazaki Y. Physiological effects of walking in Shinjuku Gyoen, a large-scale urban green area. Jpn J Physiol Anthropol. 2011;16:133-9. (in Japanese)

16. Kondo T, Takeda A, Kondo S, Kodajima N, Kobayashi I, Murakami M. Effects of physiological human adaptation of forest bathing, or Shinrin-yoku, in Tama-city of Tokyo. J Adaptation Med. 2014;18:23-8. (in Japanese)

17. Higgins JPT, Green S Cochrane handbook for reviews of interventions version 5.1.0 (updated march 2011). The Cochrane collaboration, 2011. Available from http://handbook-5-1.cochrane.org/.

18. Ogushi Y, Kimura T, Suzukamo Y, Furuhara S. Effects of various health practices on quality of life: estimation of a health promotion program at Ohito Zuisenkyo. MOA Health Sci Found Res Rep. 2000;9:13-21. (in Japanese)

19. Takayanagi K, Hagihara $Y$. To extend health resources in a forested hospital environment: a comparison between artificial and natural plants. J Jpn Mibyou Syst Assoc 2005; 11: 247-259.

20. Tsunetsugu Y, Park BJ, Ishii H, Hirano H, Kagawa T, Miyazaki Y. Physiological effects of Shinrin-yoku (taking in the atmosphere of the forest) in an old-growth broadleaf forest in Yamagata prefecture, Japan. J Physiol Anthropol. 2007;26:135-42.

21. Kozaki T, Ishibashi K, Horinouchi K, Noguchi J, Hashitomi K, Yasukouchi A. Effects of basking in the forest on physiological responses. Jpn J Biometeor. 2007:44:105-10. (in Japanese)

22. Furuhashi S, Park BJ, Tsunetsugu Y, Hirano H, Kagawa T, Miyazaki Y. Physiological evaluation of the effects of Shinrin-yoku (taking in the atmosphere of the forest) in Kayanodaira highland, Kijimadaira Village, Nagano prefecture. Kantou Shinrin Kenkyu. 2007;58:219-22. (in Japanese)

23. Park BJ, Tsunetsugu Y, Kasetani T, Kagawa T, Miyazaki Y. The physiological effects of Shinrin-yoku (taking in the forest atmosphere or forest bathing): evidence from field experiments in 24 forests across Japan. Environ Health Prev Med. 2010;15:18-26.

24. Lee J, Park BJ, Tsunetsugu Y, Kagawa T, Miyazaki Y. Physiological benefits of forest environment: based on field research at 4 sites. Nihon Eiseigaku Zasshi (Jpn J Hyg). 2011;66:663-9. (in Japanese)

25. Sung J, Woo JM, Kim W, Lim SK, Chung EJ. The effect of cognitive behavior therapy-based "forest therapy" program on blood pressure, salivary cortisol level, and quality of life in elderly hypertensive patients. Clin Exp Hypertens. 2012;34:1-7.

26. Mao GX, Cao YB, Lan XG, He ZH, Chen ZM, Wang YZ, Hu XL, Lv YD, Wang GF, Yan J. Therapeutic effect of forest bathing on human hypertension in the elderly. J Cardiol. 2012;60:495-502.

27. Kondo T, Takeda A, Kobayashi I, Mitsuyoshi Y. Positive physiological aroma effects of Shinrin-yoku in elderly persons. Aroma Res. 2011;12:161-5. (in Japanese)

28. Kondo T, Takeda A, Hosoya R, Murakami M, Kobayashi I, Takeda N, Yatagai M, Shimomura Y. Positive physiological adaptation effects of Shinrin-yoku. J Adaptation Med. 2011;14:60-7. (in Japanese)

29. Kondo T, Takeda A, Kobayashi I, Yatagai M. Positive healthy physiological effects of Shinrin-yoku in human. J Jpn Soc Balneol Climatol Phys Med. 2011;74:169-77. (in Japanese)

30. Takeda A, Kondo T, Takeda N, Okada R, Kobayashi I. Good mind-healing and health keeping effects in the forest walking. Heart. 2009;41:405-12. (in Japanese)

31. Kondo T, Takeda A, Takeda N, Shimomura Y, Yatagai M, Kobayashi I. A physio-psychological research on Shinrin-yoku. J Jpn Soc Balneol Climatol Phys Med. 2008;71:131-8. (in Japanese)

32. Takeda A, Kondo T. Good mind-healing and health keeping effects in the forest walking. J Rehabil Sport. 2009;28:30-5. (in Japanese)

33. Kondo T, Takeda A, Aoyagi N, Seki K, Takeda N, Kobayashi I, Shimomura Y, Murakami M, Yatagai M. Good psychological and physiological aroma effect: Shinrin-walking in the elderly persons. Aroma Res. 2009;10:150-5. (in Japanese)

34. Kondo T, Takeda A, Takeda N, Shimomura Y, Yatagai M, Kobayashi I, Seki K, Fukumura K, Murakami M, Yatagai M, Tomioka A. A physiological research on shinrin-yoku: analysis of its mind-healing and health keeping effect in the Kayaba forest walking. Paz-Bull. 2009;4:435-42. (in Japanese)

35. Kondo T, Takeda A. Physiological and psychological effects of Shinrin-yoku in elderly persons. Jpn J Clin Sports Med. 2009;17:122-8. (in Japanese)

36. Markevych I, Thiering E, Fuertes E, Sugiri D, Berdel D, Koletzko S, von Berg A Bauer CP, Heinrich J. A cross-sectional analysis of the effects of residential greenness on blood pressure in 10-year old children: results from the GINIplus and LISAplus studies. BMC Public Health. 2014;14:477.

37. Dayawansa S, Umeno K, Takakura H, Hori E, Tabuchi E, Nagashima $Y$, Oosu H, Yada Y, Suzuki T, Ono T, Nishijo H. Autonomic responses 
during inhalation of natural fragrance of Cedrol in humans. Auton Neurosci. 2003;108:79-86.

38. Song C, Ikei H, Lee J, Park BJ, Kagawa T, Miyazaki Y. Individual differences in the physiological effects of forest therapy based on type $a$ and type $B$ behavior patterns. J Physiol Anthropol. 2013;32:14.

39. Wilder J. The law of initial values in neurology and psychiatry. J Nerv Ment Dis. 1957;13:73-86.

40. Tsunetsugu Y, Miyazaki Y. Correlation between baseline value and amount of change in salivary cortisol concentration and salivary immunoglobulin a concentration. J Physiol Anthropol. 2007;26:612.

41. Song C, Ikei H, Miyazaki Y. Elucidation of a physiological adjustment effect in a forest environment: a pilot study. Int J Environ Res Public Health. 2015;12:4247-55

42. Ministry of Health, Labour and Welfare. Ministerial Notification No. 430 of the Ministry of Health, Labour and Welfare. 2012. http:/www.mhlw.go.jp/file/06Seisakujouhou-10900000-Kenkoukyoku/0000047330.pdf. Accessed 15 Aug 2016.

43. A committee of the Health Science Council of the Ministry of Health, Labour and Welfare. Supplement of "The second term of National Health Promotion Movement in the twenty first century (Health Japan 21 (the second term))" (in Japanese). 2012. http://www.mhlw.go.jp/bunya/kenkou/ dl/kenkounippon21_02.pdf. Accessed 15 Aug 2016.

Submit your next manuscript to BioMed Central and we will help you at every step:

- We accept pre-submission inquiries

- Our selector tool helps you to find the most relevant journal

- We provide round the clock customer support

- Convenient online submission

- Thorough peer review

- Inclusion in PubMed and all major indexing services

- Maximum visibility for your research

Submit your manuscript at www.biomedcentral.com/submit
Biomed Central 